\title{
EL ESTADO AUTONÓMICO DESDE LA PERSPECTIVA DE ANDALUCÍA
}

\author{
GERARDO RUIZ-RICO RUIZ \\ Profesor Titular de Derecho Constitucional \\ Universidad de Jaén
}





\title{
EL ESTADO AUTONÓMICO DESDE LA PERSPECTIVA DE ANDALUCÍA
}

POR

\author{
GERARDO RUIZ-RICO RUIZ \\ Profesor Titular de Derecho Constitucional \\ Universidad de Jaén
}

\section{LA POSIBLE REFORMA CONSTITUCIONAL ANTE CONCEPTOS DE LA MITOLOGÍA NACIONALISTA: AUTODETERMINACIÓN, ESTATUTO PARTICULAR, HECHO DIFERENCIAL GLOBAL}

Resulta ya casi un tópico iniciar cualquier estudio sobre la organización territorial diseñada por la norma fundamental de 1978 con calificativos tales como "indefinido", "desconstitucionalizado" o "abierto»1; por indicar sólo algunos adjetivos que ponen de manifiesto la

1 La atribución del término "desconstitucionalizado" referido al Estado Autonómico español es responsabilidad de CRUz VILLALón, al que seguimos -entiendo- la mayoría de los constitucionalistas de este país. Vid. "La estructura del Estado, o la curiosidad del jurista persa", Revista de la Facultad de Derecho de la Universidad Complutense, $\mathrm{n}^{\circ} 4,1981$.

Pero igualmente nos parece más que aceptable la matización de López Guerra a esta teoría, al sostener que en realidad, más que de un modelo desconstitucionalizado, o lo que es lo mismo, cuyas componentes y desarrollo esencial se remiten al legislador, se trataría de un modelo "abierto" o "flexible", dotado de unos elementos esenciales que le proporcionan una mínima continuidad y previsibilidad. Vid. L. López GuerRA, "Modelo abierto y modelo cerrado del Estado de las Autonomías", en Asimetría y cohesión en el Estado Autonómico, Jornadas sobre el Estado Autonómico: integración y eficacia. En Ministerio de Administraciones Públicas. Serie Administraciones territoriales, Madrid, 1997, pág.39. 
dificultad para precisar el marco constitucional de la forma de Estado. Por esta razón, y mucho más ante la perspectiva que está tomando hoy en España el debate político sobre el futuro del Estado Autonómico, cobra sentido intentar averiguar si sería posible satisfacer, con los actuales parámetros de constitucionalidad, una demanda en favor de la autodeterminación de una parte del territorio nacional.

Obviamente la respuesta a esta cuestión dependerá en primer lugar de la traducción que se proponga del concepto mismo de "autodeterminación". Lo que a su vez nos conduce invariablemente formular nuevas preguntas necesitadas de aclaración. Por ejemplo, es necesario concretar si lo que se reclama en realidad no es tanto el reconocimiento en abstracto de un derecho a autodeterminarse, esto es, a la pura y simple secesión territorial, o bien se trata tan sólo de consagrar un derecho "en diferido", es decir, se consagra como gesto simbólico en el título dedicado a los principios fundamentales, pero no se ejercita de forma inmediata. Pero además, sea o no una facultad ejercitable en cualquier momento o la simple conquista —imposición, más bienfrente al Estado central, seguirian sin resolverse todas las dudas sobre el alcance y las consecuencias de aquella segregación sobre el resto del ordenamiento constitucional y, en especial, sobre el sistema autonómico.

Como se sabe, el punto de partida de estas expectativas, que traspasan desde luego la dimensión asimétrica implícita en la Constitución territorial, hay que fijarlo en la desaparición de las mayorías absolutas que, a partir de 1993, hace depender la estabilidad del Gobierno de la nación del apoyo parlamentario de las minorías nacionalistas pertenecientes a las Nacionalidades Históricas catalana y vasca (Convergencia i Uniò y Partido Nacionalista Vasco). Este proceso se ha acentuado especialmente en esta última legislatura, hasta el punto - como recordaremos en su momento- de poner en cuestión una buena parte de los principios característicos de la forma de Estado, cuando no se llega a utilizarlos como "moneda de cambio" con que obtener una mejor dosis de gobernabilidad o, en algunos casos también, la confianza parlamentaria para algún Ejecutivo regional.

Frente a este tipo de reclamaciones políticas, y a veces institucionales de algunas Comunidades Autónomas (CC.AA.), cabe oponer algunas opciones hipotéticas, como respuestas desde y dentro del sistema.

En efecto, se apunta últimamente una inclinación hacia la remodelación en clave federal, en materia de participación de las CC.AA. en 
aquellos procesos decisionales relativos a la formación de la voluntad estatal ante la UE. Ésta sería una alternativa viable que parece contar incluso con el beneplácito de las formaciones nacionalistas. Tiene además pleno sentido si se tiene en cuenta la cesión de soberanía a esa organización supranacional (factor de globalización) y la afectación de competencias (factor de legitimación). Indirectamente así se les estaría reconociendo a las entidades sub-estatales un status político superior al de simple entidad colaboradora en la ejecución del ordenamiento comunitario europeo.

Ahora bien, subsisten aún no pocas dificultades que impiden la evolución del Estado Autonómico español hacia una forma federal clásica, ya que ésta nunca ha satisfecho - ni conviene, diríamos mejorlos propósitos de los nacionalismos periféricos.

$Y$ sin embargo no cabe duda de que la forma en que el sistema autonómico se ha desarrollado - hipótesis improbable en sus orígenes- prácticamente lo ha convertido en un " modelo transitorio" que tiene en el Estado Federal su meta natural. Aunque para ello sea imprescindible también acometer algunas reformas que hoy se encuentran en una fase de absoluta parálisis parlamentaria ${ }^{2}$.

Inclusive desde el punto de vista del sistema de fuentes, una dimensión en apariencia alejada de la evolución de la organización territorial, se observa también una "lógica federal", al comprobar la relevancia que está teniendo ya la Sentencia del TC a propósito del principio de supletoriedad (STC 61/1997), donde parece inclinarse por el principio de la separación entre ordenamientos (del Estado central y de las CC.AA.). Cada uno de ellos estaría dotado de sus respectivos y exclusivos ámbitos competenciales, sin que sea posible predicar del central-estatal el carácter de ordenamiento universal y completo. Este último no puede jugar - a partir de la resolución mencionada- el papel de derecho subsidiario que se aplica siempre en defecto del autonómico/regional, cuya característica principal sería su naturaleza incompleta y materialmente delimitada ${ }^{3}$.

2 Las noticias más recientes de que disponemos indican que el proyecto de reforma constitucional del Senado, iniciado en la anterior legislatura ha sido waparcado" hasta la próxima, al parecer por la escasa conveniencia de poner en discusión una modificación constitucional que evidenciaría el total desencuentro en este tema entre partidos de ámbito estatal y formaciones nacionalistas.

3 Vid. J. L. Requejo Pagés, «El Estado Autonómico: ¿un modelo transitorio?", en Cuadernos de Derecho Público, n. ${ }^{\circ} 1,1997$, pág. 157 y ss. 
Pero de regreso al planteamiento inicial, lo primero que debemos plantearnos es si cabe reformar la CE para introducir un derecho a la autodeterminación, sea o no con ejercicio diferido. Entiendo que este aspecto de la cuestión nos conduce a su vez al problema de la existencia de límites materiales implícitos a la reforma constitucional.

Como se sabe, nuestra Ley Fundamental no ha previsto de forma expresa ninguna restricción de este orden a la libertad de un futuro poder constituyente que ponga en marcha alguno de los proceso de revisión constitucional regulados en el Título X. Aunque también es cierto que la teórica ausencia de las denominadas "cláusulas de intangibilidad" va a quedar doblemente compensada.

En primer lugar, porque las condiciones que se imponen por el artículo 168 para impulsar y aprobar una modificación de algunos de los preceptos contenidos en su "reserva material" son de tal calibre y dificultad que, en la práctica, operan como un mecanismo que asegura la intocabilidad de los mismos ${ }^{4}$.

Como segundo argumento hay que hacer referencia a la tesis doctrinal - propuesta por Pedro de Vega- sobre la ilicitud de cualquier intento de modificar los principios fundamentales del régimen democrático. En este sentido, no obstante, quizás fuese necesario añadir una matización. Porque, en efecto, estamos totalmente de acuerdo con aquellas posiciones doctrinales que defienden la hipotética ilegitimidad de una revisión constitucional que pretenda subvertir el principio democrático para dar paso a un sistema político, en el cual se haya renunciado a la propia soberanía popular 5 .

Pero a continuación distinguiríamos esta indirecta limitación material, cuyo destino final no sería sino el de proporcionar una fundamentación jurídica a la posible involución política hacia un sistema autoritario, de aquella eventual reforma que aspire a modificar los valores básicos y principios esenciales de un determinado régimen constitucional. En el caso español, uno de estos elementos básicos que carac-

4 O como sostiene Pérez RoYo: «Ante la imposibilidad de introducir cláusulas de intangibilidad, como se hubiera deseado, (...)para impedir de iure el cambio de la Constitución en determinados contenidos, el Constituyente español ha buscado un rodeo para impedir de facto tal cambio. De ahí la artificiosidad del precepto (art. 168, CE), obligado a decir y proteger lo que se quiere decir y proteger, pero sin poderlo afirmar expresamente". Vid. J. Pérez Royo, La reforma de la Constitución, Congreso de los Diputados, Madrid, 1987.

5 Esta interpretación tiene en Pedro de Vega su principal exponente. Vid. La reforma constitucional y la problemática del poder constituyente, Madrid, 1985. 
terizan el orden político-constitucional implantado en 1978 viene configurado por el principio de unidad (art. 2, CE), como presupuesto constitutivo de un concreto modelo de Estado y límite a su vez de la descentralización político-administrativa que se pueda alcanzar desde el ejercicio del derecho a la autonomía.

De este modo, mientras que la supuesta reforma constitucional para sustituir un sistema democrático y de libertades quedaría - siempre en un plano teórico- fuera de esos límites materiales implícitos de la reforma constitucional, por contradecir abiertamente los principios que inspiran el constitucionalismo moderno, la consagración de un "ius secessionis" en el texto de la norma fundamental representaria únicamente una modificación cualitativa de la forma de Estado inicialmente diseñada. Ciertamente este cambio supondría de hecho la instauración de un régimen constitucional diferente al que está actualmente vigente en nuestro país ${ }^{6}$ al afectar el principio de la soberanía nacional "no territorializada" (art. 1-2..$^{\circ}$. Aunque como hipótesis nos parece perfectamente legítima, siempre que se realice conforme a los procedimientos democráticos que están reglados en el Título $X$ de la CE de 1978.

Lo que no creemos de recibo, ni aceptables desde una óptica jurídico-constitucional, son manifestaciones como las que en ocasiones tienen lugar en el debate político sobre la potencial compatibilidad del reconocimiento del derecho de autodeterminación con el actual ordenamiento constitucional. Véase un buen ejemplo de esta actitud "oportunista" en la resolución aprobada por el Parlamento de la Generalidad de Cataluña en octubre de 1998. A nosotros, por el contrario, nos parece que esta iniciativa parlamentaria se movería en el terreno simbólico $y$ testimonial, enfocada por tanto a un electorado de signo nacionalista; nunca ha intentado materializarse con posterioridad mediante propuestas concretas, orientadas a la consecución del objetivo marcado por aquella resolución.

6 En contra nuestra - al menos así lo interpretamos nosotros- se ha mantenido por Rupérez que «el reconocimiento de este derecho por una revisión de la Constitución no implicaría (...) un cambio de la forma de Estado consagrada o, mejor dicho, permitida, por el Texto de 1978». En su opinión -algo que no llegamos a compartir completamente- «lo que se estaría llevando a cabo es un cambio en la manifestación estructural concreta del Estado Federal admitido por el Constituyente originario (...) de un Estado políticamente descentralizado sin derecho de secesión, se pasaría a uno con este derecho". Vid. "La Constitución española de 1978 y la problemática de la autodeterminación", en Ciudadanos e Instituciones en el constitucionalismo actual (coord. J. Asensı SabateR), Valencia, 1997, pág. 722. 
El reconocimiento de un derecho a la autodeterminación implica por fuerza una modificación de la CE. No sólo porque repercute directamente sobre el principio de unidad territorial, cuya efectividad queda supeditada entonces a que se ejercite o no por un poder constituido ese derecho; también supone una contradicción conceptual y a priori con el principio de soberanía nacional, tal y como fue concebido en el proceso constituyente. Ambos elementos, característicos de nuestra forma de Estado, dejarían de tener virtualidad normativa alguna cuando se activara un proceso de segregación por parte de una Comunidad Autónoma. La razón es bastante obvia: si la Constitución representa la condición de validez de las demás disposiciones jurídicas, así como de la actuación de los poderes públicos, cómo se explica que pueda legitimar su propio incumplimiento. Este resultado parece ineludible desde el momento en que el ejercicio del derecho a autodeterminarse se opone de una manera insuperable a los principios fundamentales del sistema autonómico (unidad y soberanía nacional).

El segundo interrogante - una vez admitida la posibilidad de una "lícita" modificación constitucional con este propósito- se centraría en el modus operandi de la reforma. La única alternativa viable, en el supuesto de que se quiera incluir en el articulado constitucional alguna expresión de este ius secessionis, sería iniciar el procedimiento agravado de reforma del artículo 168, tanto por su contradicción con algunos de los preceptos del Título Preliminar, como por el hecho de que la eliminación de estos componentes esenciales de la forma de Estado conlleva una práctica sustitución del poder constituyente originario.

Pero conviene no olvidar en este punto que en realidad son dos las reclamaciones que se están apoyando en este momento desde los nacionalismos periféricos. En efecto, si desde la CA del País Vasco se insiste en el reconocimiento constitucional de un derecho a la autodeterminación - cuando no de la independencia sin condiciones formalconstitucionales- en la CA catalana el núcleo esencial de la demanda se centra en un modelo que deje abierta la posibilidad de territorializar el principio de soberanía. Sin embargo, la inédita fórmulación de una "co-soberanía" Estado-Nacionalidad Histórica tiene - inclusive para sus impulsores - unos contornos todavía bastante difusos y conscientemente indefinidos.

Para quienes postulan el primero de esos objetivos, parece como si la separación de una parte del territorio nacional del Estado no llegaría a afectar necesariamente a la articulación del resto. El razona- 
miento que se emplea intenta convencer de la necesidad de modificar únicamente el artículo 2 de la actual norma fundamental (principio unitario), lo que no puede traducirse como un cambio cualitativo de la forma de Estado, en la medida en que las demás CC.AA. seguirían dentro del marco constitucional y las relaciones entre éstas y el poder político central no sufrirían alteración alguna por el hecho de que una de ellas dejara de pertenecer al conjunto. Lógicamente este planteamiento se mueve en una dimensión política que choca frontalmente a nuestro entender - con cualquier modelo de organización territorial que mediante la constitucionalización de sus elementos más significativos pretenda tener vocación de permanencia. Por otra parte, desde la perspectiva concreta de nuestro régimen constitucional supondría un verdadero "fraude de ley" que conculcaría, jurídicamente hablando, la eficacia normativa de los presupuestos consustanciales del modelo.

En cuanto al segundo tipo de reivindicaciones, la propuesta de una eventual "co-soberanía" también viene a afectar de manera cualitativa las pautas generales y principios que configuran al actual Estado Autonómico español. De ahí que tampoco bastaría con reformar el artículo 2 de la $C E$, puesto que la interpretación de la autodeterminación en esta clave de soberanía compartida (Estado central-entidades subestatales) conlleva una vez más la imperiosa exigencia de sustituir no pocos de los elementos básicos que hoy configuran la Constitución territorial. Cuando se plantea esta formula (co-soberanía) en realidad se está intentando el reconocimiento de un status político diferencial para una parte del territorio del Estado. Pero no puede olvidarse que el otorgamiento de un trato particular -o privilegiado, sería mejor decir- entraría en colisión con los principios de solidaridad e igualdad entre CC.AA.; de manera que no sólo se vería afectado el Título Preliminar (art. 2), sino del mismo modo entendemos que habría que proceder a la reforma de una parte considerable del Título VIII.

Debemos insistir, por tanto, en que la imaginaria eventualidad de proclamar la autodeterminación entre los principios de la organización territorial del Estado resulta, desde una dimensión dogmática del problema, meridianamente incompatible con la proclamación de la unidad indisoluble del Estado español. No cabe duda de que en el examen general del texto constitucional se llegan a apreciar algunas contradicciones de principio, en algún momento expresas, que obligan a realizar una operación de equilibrio o - lo que se ha llamado muchas veces por nuestra jurisprudencia constitucional- «la ponderación de intereses 
en presencia" 7 . Sin embargo, no cabría posibilidad alguna de conciliación entre el principio unitario, como presupuesto básico del modelo territorial de Estado, y el derecho de autodeterminación. Si bien habría que puntualizar que esta oposición se produce más que con su expresión teórica formalizada, respecto sobre todo de su ejercicio concreto por parte de una entidad sub-estatal. Aunque es posible alargar los argumentos hasta el punto de considerar que ambas nociones no tienen por qué ser incompatibles, lo cierto es que resulta irrefutable que la materialización de una hipótesis de segregación contradice abiertamente la garantía constitucional de la unidad. La conclusión a la que llegamos, de este modo, tiene que ver asimismo con la ilegitimidad de cualquier operación que defienda una "mutación constitucional" praeter legem (imposible - desde nuestro punto de vista- secundum legem) que bordee, mediante instrumentos político-normativos de rango jerárquico inferior la frontera del "bloque de constitucionalidad"

Antes de seguir adelante conviene advertir de la condición oportunista de este tipo de planteamientos. En efecto, en un Estado democrático que se legitima por el reconocimiento y ejercicio constante del derecho de los ciudadanos a la autodeterminación -esto es- a adoptar decisiones políticas y crear normas jurídicas- no puede decirse que en el País Vasco o Cataluña estos mismos ciudadanos estén privados de ese derecho. Lo ejercitan cada vez que se celebran elecciones y no puede decirse que estén privados de ese derecho ${ }^{8}$. Por lo demás, y como hemos advertido ya, esta autodeterminación -o "libre determinación" ${ }^{9}$ - que se reclama por el nacionalismo vasco democrático (PNV) todavía no se ha delimitado claramente, ni desde la perspectiva formal sobre el procedimiento de acceso (referéndum o reforma constitucional), ni desde el punto de vista de su alcance específico (simple proclamación formal en el texto de la Constitución, o bien ejercicio efectivo del mismo $y$, en consecuencia, secesión de una parte del terri-

7 Podríamos citar como ejemplo de paradoja constitucional explícita la desigualdad entre sexos sancionada por la CE en el sistema sucesorio a la corona. Pero lo más frecuente es encontrar — como consecuencia inevitable del consenso constituyente- un cierto número de principios y derechos constitucionales cuyo ejercicio entra en potencial enfrentamiento con el mismo ejercicio de otros derechos y principios que responden ideológicamente a presupuestos contrarios. Por poner sólo algunos supuestos de contraste dogmático: propiedad privada-función social (e intervencionismo público), libertad religiosa frente a la expresa mención a la iglesia católica, o bien la satisfacción de un derecho a la educación versus libertad de enseñanza.

8 Vid. J. Pérez Royo, El País, 29 de septiembre de 1998.

9 Vid. D. López Garrido, El País, 15 de diciembre de 1998. 
torio nacional).

Con frecuencia algunos de los que lideran este tipo de formaciones nacionalistas insisten en la tarea de "medir la Constitución", para llegar a la conclusión - fácil por lo demás - de que la autodeterminación, en términos de figuración jurídica, "no cabe» en la norma fundamental de 1978. Opinión la anterior sobre la que no se mantiene tampoco una posición unánime, ya que entre sus mismos promotores hay quienes, en otras ocasiones ${ }^{10}$, consideran que las "dimensiones" del texto constitucional si permitirian incluir dentro de su marco normativo un derecho a la autodeterminación; aunque, por supuesto, no en general para todas las Comunidades sino privativo o exclusivo para las Nacionalidades Históricas.

En cualquier caso, la indeterminación sería la nota dominante a propósito de este debate. Un resultado hasta cierto punto lógico, si se tiene en cuenta que el significado del derecho a la autodeterminación territorial no tiene por qué coincidir con la independencia o secesión, exponentes emblemáticos de los derechos de un pueblo sojuzgado o colonizado. Parece existir una cierta homogeneidad doctrinal a la hora de considerar que el derecho a la autodeterminación sólo podría ser interpretado como legítima reclamación de independencia en aquellas circunstancias en las que los ciudadanos a los que se niega la oportunidad de configurar sus propias instituciones de "autogobierno": (colonias, pueblos oprimidos militarmente, minorías que no tienen reconocidos sus particularismos socio-culturales) ${ }^{11}$. Por esa razón,la invocación al derecho internacional se encontraría totalmente infundada en contextos democráticos, en los que se establecen mecanismos decisionales para la participación ciudadana.

Pese a la ausencia de una lógica secesionista en un contexto democrático, puede suceder no obstante que ésta aparezca como reivindicación - por qué no legítima- de una nacionalidad que expresa una voluntad mayoritaria por separarse de la organización es-

10 Resolución del Parlamento catalán de 1 de octubre de 1998, donde rechazaba expresamente la necesidad de impulsar un procedimiento de reforma de la CE de 1978, al considerar que la autodeterminación no era incompatible con el actual marco constitucional. Sin embargo, la ambigüedad, cuando no la contradicción interna de la declaración parlamentaria, permitió a los independentistas catalanes, acto seguido ( 2 de octubre), presentar una nueva propuesta en la misma sede institucional, solicitando la celebración de un referéndum de autodeterminación.

11 A la Carta de las Naciones Unidas de 1945, hay que añadir las Resoluciones $1415(\mathrm{XV})$ y 2625 (XXV) de la AGNU. 
tatal a la que pertenece originariamente. En este sentido, el derecho a la autodeterminación se plasma en el ejercicio de un poder político ilimitado y originario a la hora de decidir sobre la propia forma política. Por este motivo, carece de sentido que un Estado reconozca a sus entidades territoriales mecanismos constitucionales con los que romper precisamente con esa legalidad constitucional 12 , en virtud de un más que improbable "derecho colectivo" a segregarse territorialmente ${ }^{13}$.

Lo anterior tiene relación directa con la persistencia en el Estado Autonómico español de ciertos componentes confederales ${ }^{14}$, un factor que dificulta la potencial evolución del modelo hacia una estructura federal ${ }^{15}$. La dinámica centrífuga imparable a la que está siendo sometido el funcionamiento del sistema de las autonomías no favorece los ensayos de ingeniería constitucional que intenten una interpretación en clave de federalización. El resultado de estas tensiones, lideradas por los movimientos nacionalistas, parece estar conduciendo hacia una fórmula prácticamente inédita que no encaja en ninguna de las formas

12 Vid. J. J. Solozábal Echavarría, Las bases constitucionales del Estado Autonómico, Madrid, 1998, pág. 104.

13 Para J. F. López Aguilar, es un despropósito sostener la existencia de un derecho - a la autodeterminación-que "no tiene sujeto, ni acción, ni régimen de ejercicio, ni instancia ante que invocarlo», en "¿Con-federalismo en España?: el pálpito nacionalista en la España autonómica como problema político y problema constitucional", en Claves para una reforma constitucional (A. PORRAS y G. RuIz-Rıco, coords.). En prensa.

14 Efectivamente, existen estos componentes "confederales» en el Estado de las Autonomías español, cuya expresión más palmaria se puede localizar en el discurso anti-constitucionalista y anti-nacional de una buena parte de la clase política de Cataluña y el País Vasco, como en iniciativas como la de la Asamblea de Municipios vascos, desde donde se quiere impulsar la generación de poder constituyente originario para el conjunto del País Vasco (francés, español y Navarra); sin olvidar algunas de las manifestaciones que se han expresado en las reuniones de los partidos nacionalistas de las Comunidades Históricas (Barcelona, Vitoria, Santiago de Compostela) a través de las cuales se ha defendido lo que sería un proyecto político muy cercano a la confederación.

15 Para J. AcosTA, por el contrario, la intensificación que está teniendo lugar de estos elementos confederales que subsisten en el Estado Autonómico estarían generando la necesidad de implantar un Estado de corte federal. No obstante, estamos perfectamente de acuerdo con este autor cuando subraya que frente a la desnaturalización que está sufriendo el Estado Autonómico la creación de un Estado federal español sería un freno a la desintegración de la soberanía del constituyente». Vid. "Rasgos y prácticas de carácter confederal en el Estado Autonómico español". Comunicación presentada al XII Congreso Nacional de la Asociación Española de Derecho Constitucional. Taller sobre "Simetría y asimetría en el estado Autonómicon. Alicante, 1999. 
de Estado con fuerte grado de descentralización política.

Es obvio que para los nacionalismos interesa menos una forma federal de Estado, en tanto en cuanto se trata de un modelo construido sobre la idea de una soberanía nueva pero siempre potencialmente unificadora y, por supuesto incompatible con la conservación de "soberanías originarias territoriales", a las que aquéllos no quieren en ningún caso renunciar, si es que logran algún día definirlas como expresión de una voluntad popular irrefutable y rotunda. En definitiva, la construcción de una forma estatal de este tipo exige la renuncia del poder político estatal en favor de una soberanía federal con vocación centralizadora.

Por este tipo de razones es igualmente posible - por muy paradójico que resulte en principio- que estas mismas fuerzas políticas prefieran explotar al máximo los límites de un Estado autonómico desigual o asimétrico, siempre "abierto" a nuevas concesiones territoriales, que explorar opciones con las que profundizar más si cabe en los niveles generales -léase multilaterales- de descentralización política. En este sentido, la lucha permanente por ganar nuevas competencias está generando unos efectos perversos sobre la propia identidad constitucional del sistema.

Sospechamos que detrás de este pressing o pulso al poder politico central lo que en realidad se está reclamando no sería sino la constitucionalización de un estatuto particular, legitimado por diferencias lingüísticas y forales - probablemente más que por cuestiones de singularidad cultural- y sancionado constitucionalmente en su caso, para así "marcar distancias" con el resto de las Comunidades.

Se trata, por tanto, de un enfoque -llamémosle - "quebecquiano" de los márgenes de flexibilidad implícitos en el modelo autonómico, alejado por supuesto de las alternativas federales que representan por lo general la asunción del igualitarismo y la multilateralidad de las relaciones centro-periferia.

En apoyo de esta tesis la propia Constitución contempla ya inicialmente una aparente distinción de status entre "nacionalidades" y "regiones" (art. 2), que sirve muy bien a los propósitos que se han marcado algunos de estos nacionalismos. Aún cuando el significado efectivo de esta terminología se ubica más en lo simbólico lo socio-cultural) y menos en lo jurídico (o estatutario), lo cierto es que no deja de ser útil para justificar la idea de un trato desigual entre territorios del Estado y, por ende, una mayor dotación de poder político o uplus de poder" para unos respecto de otros. 
Sin embargo, un examen detenido de aquellas formas estatales con un notable grado de descentralización nos permitiría reconocer la presencia de estatutos particulares como regla habitual de los Estados regional/autonómicos. Ocurre así en la Constitución republicana de 1931,como en experiencias similares del derecho comparado: caso de las Regiones con Estatuto especial de la Constitución italiana de 1948 o la futura organización político-territorial en Gran Bretaña cuando culmine el proceso de devolution.

Aunque sobre el federalismo canadiense se ha escrito ya lo suficiente como para haber superado cualquier pretensión "mitificadora", todavía algunas formaciones nacionalistas ven en las históricas reclamaciones de Quebec un referente básico con el que defender la demanda de un tratamiento constitucional específico. Sin embargo, y en contra de lo que pudiese pensarse, el ejemplo canadiense no responde exactamente al principio de asimetría federal. Dentro del texto constitucional de ese país, no ha quedado sancionado en ningún instante el otorgamiento de un status particular y exclusivo a aquella provincia francófona ${ }^{16}$.

La comprobación de los aspectos verdaderamente singulares para la provincia de Quebec, desde una óptica constitucional, posiblemente defraude las expectativas de una hipotética importación de ese modelo. Porque aparte la conservación de un derecho civil propio, la co-oficialidad lingüística en las instituciones federales y provinciales y la competencia exclusiva de estas últimas en materia educativa, no puede predicarse de este territorio un status particular que lo diferencie cualitativamente de las demás provincias dentro de la Federación ${ }^{17}$.

16 Vid. A. Salz Arnalz, "Simetría y asimetría en el Estado autonómico español». Comunicación presentada al XII Congreso Nacional de la Asociación Española de Derecho Constitucional. Taller sobre "Simetría y asimetría en el estado Autonómico". Alicante. 1999. Del mismo autor, "Estado federal y estatuto particular. La posición constitucional de la provincia de Quebec en la federación canadiense", Madrid, 1997. En relación con este caso, vid. también A. RuIz RoBledo, "Canadá, un federalismo casi olvidadon, en Revista de Estudios Políticos, n. ${ }^{\circ} .69$. Vid. Tania Grop$\mathrm{PI}$, «El problemático federalismo canadiense», en Claves para una reforma constitucional (A.PORRAS y G.RuIz-Rıco, coords.). En prensa.

17 Para SAIZ ARNaIz podría considerarse no obstante que Quebec disfruta de un estatuto singular de facto - no estrictamente constitucional-, sobre todo al ejercer al máximo de sus posibilidades las competencias que tiene asignadas, especialmente en materias como financiación, política de inmigración o policía. Vid. "Estado federal y "estatuto particular"...", cit., págs. 145-147. 
Como hemos señalado, la propia Constitución ofrece motivos que impulsan la dialéctica de la desigualdad territorial. Si antes era cuestión de nomenclaturas con las que pueden autodefinirse las CC.AA. (nacionalidad o región), ahora se trata de determinar el alcance que tiene los llamados "hechos diferenciales", en buena medida punto de partida de las demandas de autodeterminación y/o co-soberanía.

Frente a la puesta en escena de uno de los mejores argumentos para obtener un estatuto particular, la respuesta que se ha dado por el constitucionalismo patrio ha sido la de intentar averiguar la relevancia constitucional y las posibles consecuencias jurídicas de una realidad que enlaza directamente con una de las características más emblemáticas de nuestro Estado Autonómico.

Efectivamente, la inevitable "asimetría" del modelo territorial tendría diferentes niveles de intensidad ${ }^{18}$. En primer lugar, se podría hablar de una simple desigualdad competencial, resultado de un principio dispositivo que permite a las CC.AA. asumir títulos y atribuciones no siempre idénticas en sus respectivos EE.AA. En algunos casos, además, estas diferencias se justifican por la existencia de elementos fácticos que no pueden ser obviados por el poder estatuyente (costa marítima, espacios naturales con alto valor ecológico, situaciones específicas de algún sector económico de la Comunidad, etc.).

El grado siguiente en los niveles de asimetría constitucional estaría configurado por aquellas particularidades sociales y jurídicas con las que se identifica y encuentra una personalidad propia una Comunidad. Se trataría de los auténticos "hechos diferenciales", expresamente formulados por la norma fundamental de 1978 o, en todo caso, consecuencia directa de las previsiones constitucionales ${ }^{19}$. Por lo general se presentan en las denominadas "Nacionalidades Históricas", seguramente porque son razones de esta naturaleza las que mejor explican su conservación hasta el presente.

A partir de este razonamiento, podríamos convenir que los únicos diferenciales fácticos relevantes constitucionalmente $y$, por consi-

18 Vid. J. Garcia RocA, «España asimétrica (Descentralización territorial y asimetrías autonómicas: una especulación teórica)", en Asimetría y cohesión en el Estado Autonómico, cit., pág. 51 y ss.

19 Vid. G. TruJlLLo, ulntegración constitucional de los hechos diferenciales y preservación de la cohesión básica del Estado autonómico», en Asimetría y cohesión en el Estado Autonómico, Instituto Nacional de Administración Pública, Madrid, 1997. 
guiente, en los que estaría justificado una desigualdad territorial entre CC.AA., serían aquellos que han sido formalizados en disposiciones concretas de nuestra Carta Magna. La conclusión, de este modo, se nos presenta ya bastante obvia. Los hechos diferenciales de naturaleza constitucional se reducirían a un número escaso de elementos distintivos de alcance por otra parte limitado: la lengua vernácula de carácter oficial (art. 3), el derecho civil foral (art. 149-1. ${ }^{\circ}-8$ ) y un régimen fiscal exclusivo (para el País Vasco, ex Disposición Adicional Primera; para las Islas Canarias, en virtud de la Disposición Adicional Tercera) ${ }^{20}$.

Una vez realizada la operación inicial que nos permite identificar estos elementos diferenciales desde el punto de vista territorial, lo que importa en este momento es evitar el intento de legitimar, a partir de los mismos, la posterior configuración de un "hecho diferencial global» o "aspiración diferenciadora global»21, desde el cual se pueda sostener la reclamación de un «estatuto particularnal borde mismo - si no abiertamente fuera- de la forma de Estado constitucionalizada.

Por nuestra parte, esta última interpretación de los "hechos diferenciales" no nos parece aceptable, sobre todo cuando estamos convencidos de que éstos tienen en el texto fundamental un significado material restringido, en la medida en que se introduce con ellos lo que sería una excepción al principio de igualdad inter-territorial, sancionado expresamente en varios de sus preceptos (art. 138-2. , $139-1 .^{\circ}$ y $149-1 .^{\circ}-1$ ). De la misma forma que tampoco resultaría correcto, al menos desde una óptica estrictamente jurídica, extraer consecuencias más allá de lo puramente simbólico y testimonial, a la decisión estatutaria de reconocerse a sí misma como "nacionalidad». La diferente nominación con que una Comunidad se identifica frente al Estado y las demás Comunidades no es motivo suficiente para respaldar tratamiento privilegiado alguno en el orden competencial y financiero. Como hemos sostenido en otro lugar, la utilización de esta

20 Vid. J. Tajadura TEJADA, "Los hechos diferenciales constitucionalmente relevantes". Comunicación presentada al XII Congreso Nacional de la Asociación Española de Derecho Constitucional. Taller sobre "Simetría y asimetría en el estado Autonómico". Alicante, 1999.

21 Gumersindo TruJiLlo ha definido con precisión esta otra especie de "hecho diferencial global" como "la pretensión de un status constitucional autonómico específico y favorecedor de esa Comunidad respecto de las restantes", en Integración constitucional..., cit., pág. 21. 
terminología hace patente en todo caso el nivel de personalidad histórica y cultural, pero no necesariamente una voluntad política de naturaleza estructural22.

En apoyo a esta tesis debemos recordar la ampliación del número de CC.AA. que progresivamente han incorporado la adjetivación de "Nacionalidad" a la hora de identificarse estaturiamente, sin que ello haya significado de manera automática una elevación en su techo de autogobierno regional23.

Pero precisamente el carácter limitativo con el que la CE de 1978 ha concebido el reconocimiento de los "hechos diferenciales» representa un argumento en contra de la extensión de los mismos al conjunto de CC.AA. En algunos casos, es la propia realidad la que impide una potencial expansión del distintivo territorial; pensemos en la imposibilidad de otorgar rango de oficial a una lengua diferente al castellano en una Comunidad donde nunca se ha hablado otra lengua distinta a ésta. En otros casos, es la realidad jurídica (derecho civil foral)que entronca con la historia lo único que justifica un tratamiento singular por parte de la Constitución. Pero en ningún caso, esta clase de excepciones al principio de igualdad inter-territorial pueden constituir la base de una interpretación del "hecho diferencial», en virtud de la cual se favorezca una demanda política en favor del eventual reconocimiento del derecho de autodeterminación o la re-lectura del principio de soberanía popular.

Con frecuencia se ha puesto de manifiesto la conveniencia de reformar la Constitución territorial para que incorporar en ella lo que los EE.AA. y la propia experiencia autonómica han significado como desarrollo del Título VIII24. Si con suficientes motivos se ha afirmado lo anterior, una vez concluida una primera etapa en la que se había remitido al legislador (orgánico y estatutario) la principal responsabilidad de concluir ese diseño inacabado por el constituyente, hoy este razonamiento cobra un inédito vigor.

22 Vid. G. Ruız-Rıco, «El Estado autonómico en España: algunas reflexiones críticas sobre el sistema de financiación autonómica", en Cultura Andaluza (J. HuRtado Sáez y E. Fernández de Paz, eds.), Sevilla, 1999, pág. 161.

23 Algunos Estatutos de Autonomía (EE.AA.) pertenecientes a Comunidades que podrían ser calificadas dentro de ese grupo hacen referencia a la identidad histórica (Aragón, Baleares), se autodefinen en cierto modo como "Nacionalidad" (Andalucía), o bien incluyen otra denominación singular(caso del "Reino" de Valencia).

24 Vid. P. Cruz Villalón, El Estatuto de Andalucía. I. Las Competencias. Barcelona, 1990, pág. 19. 
Por lo pronto, habría que eliminar sin duda todo el bloque de disposiciones transitorias que forman parte de ese Título dedicado en buena medida al procedimiento de creación de lo que después se llamaría unánimemente el Estado de las Autonomías ${ }^{25}$. Pero superada ya por la historia más contemporánea la originaria Constitución territorial, es necesario plantearse ahora la posibilidad de una revisión de mayor calado, lo que no significa activar de inmediato alguno de los procedimientos que se han previsto para modificar el texto aprobado en 1978. Se trata tan sólo de debatir sobre aquélla, o lo que es igual de "normalizar" la reforma como uno más de los mecanismos posibles de adaptación del ordenamiento constitucional a la realidad política.

Sería arriesgado promover una "mutación» en las fronteras de la constitucionalidad, que no haría sino poner en entredicho el principio básico de la eficacia normativa del texto fundamental ${ }^{26}$. Frente a esta alternativa, somos partidarios de poner en práctica una reforma constitucional mediante la cual se proceda a la modificación de la forma de Estado; fundamentalmente por la legitimación democrática que se consigue con esta segunda alternativa queda fuera de toda duda.

Ahora bien, con este planteamiento no estamos defendiendo, ni siquiera indirectamente, la oportunidad de impulsar la sustitución de los principios fundamentales de ese modelo territorial. Tan sólo queremos subrayar la preferencia de que, si en su caso se promueve un cambio en la reglas de juego en las relaciones centro-periferia, se lleve a cabo justamente con las mismas normas que han sido previstas para aprobar esa reforma.

Esto tiene mucho que ver con la propuesta "extra-constitutionem» de un supuesto "ámbito de decisión" (vasco, catalán o gallego, de todos ellos como conjunto diferenciado), en el que se centraría la propuesta y, en su caso, aprobación, de una revisión del modelo territorial27.

25 Este bloque de preceptos padecen lo que se conoce como "desuetudo"; al tratarse de normas de eficacia transitoria, en el momento en que se aplicaron y culminaron los proceso fundacionales de las CC.AA. dejan de tener operatividad en la práctica.

2 Al forzar en exceso la elasticidad de las disposiciones que forman la llamada "Constitución territorial" se correría el riesgo de producir un supuesto de "quebrantamiento" de la norma fundamental, utilizando la terminología siempre útil a estos efectos de TORRES del Moral. Vid. Introducción al Derecho Constitucional, Madrid, 1996, págs. 114-116.

27 Entre los numerosos problemas constitucionales que plantearía la celebración de un referéndum sobre la autodeterminación del País Vasco habría que destacar —a nuestro juicio- los siguientes: 
Mientras permanezca inalterado el principio de constitucionalidad nunca será posible admitir el ejercicio de una supuesta "soberanía nacional" por una parte del Estado, ni la imposición por una Comunidad de una voluntad "constituyente" a partir de ensayos institucionales -al caso, la Asamblea de Municipios vascos-que son ajenos por ahora a los sistemas de representación política creados por la Constitución y el Estatuto de Autonomía. Precisamente en el ejercicio de su competencia exclusiva sobre "organización de sus instituciones de autogobierno" (art. 148-1. ${ }^{\circ}-1, \mathrm{CE}$ ) cada Comunidad estaría en condiciones de poner en funcionamiento nuevos escenarios desde los cuales reivindicar, legítimamente, lo que esté tanto dentro como fuera del marco constitucional. Con ello estaría tan sólo haciendo uso de las potencialidades que encierra la autonomía, en cuanto derecho que no se agota con la promulgación de unas normas estatutarias, sino que, por el contrario, necesita de una permanente puesta al día, para acomodarse a las necesidades y aspiraciones de una sociedad dinámica sobre la que se proyecta. Como opción alternativa a la anterior, la propia CE otorga a las entidades subestatales la facultad de impulsar por sí mismas, ante el Parlamento central, un proyecto de reforma constitucional (art. 166).

En cualquier caso, los hechos demuestran que todavía no ha sido aprobada en su totalidad la asignatura de la «integración" por el modelo de Estado que ha sido constitucionalizado. Pendiente aún, por lo tanto, abundan en la actualidad diversas concepciones - a veces denominadas "re-lecturas" - que no hacen sino poner de manifiesto una especie de "desencuentros en la tercera fase" del proceso autonómico ${ }^{28}$.

- alcance territorial: no se ha concretado por ninguna fuerza nacionalista si debería celebrarse igualmente en Navarra, ya que sin duda sus efectos parece que alcanzarían a esta Comunidad.

- formales: no se ha afirmado si se sería necesario previamente reformar el EA del País Vasco o la Ley Orgánica sobre las distintas modalidades de Referéndum (LO 2/1980), pues en ninguna de estas normas se contempla esta posibilidad. segregación.

- sustantivos: sobre el problema de la "irreversibilidad" del proceso de

- eficacia juridica: al tratarse de una hipótesis de consulta popular del artículo $92-1 .^{\circ}$ de la CE su valor en teoría sería puramente consultivo y no vinculante jurídicamente.

28 Expresión que se emplea por Torres Vela cuando aporta la visión del problema desde la CA de Andalucia. Aun cuando ésta no ha sido expresada en forma de discurso institucional o resolución parlamentaria autonómica, creemos que ha quedado sintetizada, de manera más o menos representativa, en el discurso del Presidente del Parlamento de Andalucía. Tesis defendida por Torres Vela en su conferencia "Andalucía en el Estado Autonómico". Fundación Campalans, Barcelona. 1997, pág. 15. 
Es bastante probable que las excesivas concesiones que se han hecho a algunos nacionalismos periféricos en orden a favorecer la "gobernabilidad" del Estado central hayan provocado una dinámica imparable que, más que tender al cierre del sistema, están provocando fisuras profundas para su definitiva consolidación. Hace años, por ejemplo, no se cuestionaba la integridad territorial y hoy, sin embargo, ha pasado a ser el tema estelar del debate político-territorial.

Desafortunadas son - a nuestro juicio- algunas de las propuestas que se han lanzado con demasiada ligereza en pro de una.reforma del sistema electoral con objeto de neutralizar a los nacionalismos de algunas CC.AA., cuya colaboración para la formación y estabilidad del Ejecutivo estatal se ha demostrado indispensable en las dos últimas legislaturas ${ }^{29}$. Porque la contribución de estos partidos de ámbito no estatal -los bautizados por la politología como PANES - en la «mayoría parlamentaria de gobierno", no sólo facilita la gobernabilidad, sino también representa un factor importante de integración política entre aquellas formaciones donde existe un déficit notable de concienciación "estatal" o "constitucional".

Pero lo que resulta imposible de objetar es que la combinación de factores como el "carácter dispositivo" y el principio de igualdad inter-territorial, junto a la apertura constitucional que caracteriza el modelo de Estado Autonómico, convierten en infructuosa la pretensión de marcar diferencias de contenido en la autonomía de las CC.AA. Es indudable que no existen obstáculos jurídicos para que cualquiera de ellas inicie un proceso de reforma estatutaria para alcanzar el techo de autogobierno del que disfruten otras con mayor nivel de concienciación nacional. Así ha sucedido durante estos primeros años de experiencia de descentralización político-territorial, y nada impide que la

29 Las reacciones políticas de algunos sectores del PSOE (líder de esta corriente de opinión, Rodríguez lbarra), ante esta fuerte dependencia "nacionalista» del Gobierno central, no han llegado a concretarse todavía en una propuesta formal de revisión de la Ley electoral (LOREG), en relación con la desigualdad que se produce entre formaciones políticas que, con un mismo -o muy similar-apoyo entre el electorado, sin embargo su concentración territorial estaria beneficiando injustamente a los partidos nacionalistas con fuerte arraigo en algunas CC.AA. (CiU o PNV). Por su parte, el Coordinador de la formación política más perjudicada por la dispersión de voto ha llegado a proponer en algún momento la implantación de un sistema proporcional puro, con una sola circunscripción electoral nacional. Desde ciertos sectores doctrinales también ha habido pronunciamientos en contra de una reforma electoral con ese propósito. Vid. J. DE ESTEBAN, "Los riesgos de los nacionalismos", El Mundo, 22 de octubre de 1997. 
tendencia hacia la homogeneización sea la pauta dominante en la evolución futura de la forma de Estado. Por otra parte, hay que recordar que los EE.AA. otorgan a las propias Comunidades la potestad para impulsar, por sí mismas, esta hipotética modificación, sin el concurso necesario - al menos en la fase de propuesta- de la voluntad del Parlamento central.

A la vista de la importancia de los argumentos políticos, y -en nuestra opinión- "sedicente-constitucionales", que entroncan con el pasado, no sería demasiado absurdo preguntarnos si deberíamos estudiar algo de Historia los constitucionalistas. Formulada en términos más exactos, si habría que otorgar "sustancialidad" a las posibles explicaciones históricas por encima de la interpretación constitucional. La cuestión viene al caso - cómo no- de la relevancia que tengan los referidos "derechos históricos de los territorios forales" (Disposición Adicional) en el debate sobre la autodeterminación de una parte de del territorio del Estado. En definitiva, del significado e interpretación político-constitucional de los mismos depende en gran medida la evolución que pueda experimentar en el futuro el Estado autonómico español.

Un primer problema se plantea con ocasión de la confusión misma que existe sobre el significado de aquellos "derechos" en el seno de las formaciones políticas nacionalistas que reclaman su ejercicio. Supongamos por un momento que hubiese triunfado sobre la versión más integrista ("aranistas») aquella otra que propugnaba un mayor acercamiento a las tesis constitucionalistas ("euskalherríacos"); o que, por ejemplo también, Sabino Arana no hubiese fallecido antes de haber concretado la propuesta de una "Liga de Vascos Españolista", en la que se había pensado defender el máximo de autonomía, si bien en el seno de la unidad constitucional del Estado ${ }^{30}$. No cabe descartar la influencia que han tenido esas circunstancias personales y políticas, obviamente de naturaleza interna dentro de un partido, en la explicación sobre las razones "históricas" de las que emanan esos derechos colectivos del País Vasco.

Ahora bien si esto es así, entonces no tiene demasiado sentido buscar una fundamentación "meta-constitucional» - si no "supra constitutionem»- al reconocimiento del carácter de Nacionalidad para

30 Vid. El clarificador en este punto, análisis realizado por J. CORCUERA ATIENZA en "Nacionalismo vasco: de la reintegración foral a los derechos históricos», Cuadernos de Derecho Judicial, VI,1998, Madrid, pág. 109 y ss. 
reclamar el derecho a un estatuto particular, basándose en la concesión que hace nuestra norma fundamental en la Disposición Adicional Primera a unos "derechos históricos" que, desde un punto de vista histórico también, representan un claro modelo de indefinición.

Ciertamente, estamos de acuerdo en lo sustancial con la superación de esa dicotomía entre "nacionalidades" $y$ "naciones", y admitimos por lo tanto la existencia de hecho en España de un «Estado pluri-nacional»31: Ahora bien, no se puede olvidar que esta terminología acaba por perder su sentido jurídico, al menos desde el punto de vista del nivel real de autogobierno, desde el momento en que por un lado se produce la igualación de competencias con las Nacionalidades Históricas con la reforma de los EE.AA. de las Comunidades del 143 (a partir de los Pactos Autonómicos de 1992). Pero, además, resulta cada vez más extendida la tendencia a utilizar el título de "nacionalidad» en aquellas Comunidades que poseen algún signo de foralidad o lengua vernácula distintiva; cuando no por simple razones coyunturales que obligan a buscar apoyos parlamentarios para alcanzar la formación de un gobierno estable 32 .

De ahi que, acaso como única fórmula para detener una dinámica a la postre disgregadora, mucho antes que favorable a la integración, sea ineludible volver a emplear las técnicas paccionales que en otras ocasiones (1981 y 1992) ya se pusieron en práctica para perfilar el desarrollo del modelo. La diferencia ahora - seguimos en un terreno hipotético- consistiría en incorporar por vez primera a las formaciones nacionalistas que tengan un peso notable, si no responsabilidades de gobierno, en sus respectivas CC.AA. No puede ser de otro modo, si no se quiere dejar nuevamente abierta la posibilidad de una desordenada y particularizada evolución del sistema. Si en acuerdos autonómicos anteriores la afectación era tangencial o nula sobre las Comuni-

31 Otra cosa bien distinta es que — como advierte RuBIo LLORENTE- para que se defina formalmente de este modo sería preciso una reforma de la Constitución. Vid. "La reforma de la Constitución»m El País, jueves 10 de septiembre de 1998.

32 Un último ejemplo de superposición de esta vigente superposición -o voluntaria confusión - de un problema propio del modelo de gobierno parlamentario con un elemento característico de la forma de Estado ha tenido lugar en la CA de Baleares. Para poder contar con el apoyo de un minoritario partido nacionalista (Uniò Mallorquina) en ela formación del Gobierno autonómico tras las últimos comicios regionales (Mayo, 1999), el Partido Popular ha "ofrecido" la posibilidad de reformar su Estatuto en orden a reconocer la condición de "nacionalidad", además de un trato fiscal análogo al que goza la CA del País vasco, sólo que ésta amparada en de una previsión constitucional expresa (Disposición Adicional tercera, CE). 
dades Históricas, en este caso, al tratarse de una reforma de aspectos esenciales en su concepción del autogobierno, sería imprescindible el concurso de los nacionalismos periféricos, mucho más si son éstos mismos quienes la están proponiendo en este último período.

Quizás también, el resultado de estos "Pactos" debería conducir a desenterrar el "cadáver" del proyecto de reforma constitucional que, hasta la presente legislatura, se había consensuado en pro de una revisión en clave "federal" de la Constitución territorial. Aunque la finalidad ha de ser obviamente la de revitalizar aquella iniciativa para, a continuación, integrar en el futuro diseño algunas de las demandas políticas que se están planteando recientemente desde algunas CC.AA. En la búsqueda de este "encaje federalista" no estarían excluidas aquellas propuestas que vengan a confirmar la desigual conciencia de identidad nacional que existe, sin duda, entre ellas. Ahora bien, la plasmación institucional, y constitucional incluso, de nuevas "asimetrías" no debería traspasar nunca el riesgo de colisión con un principio consustancial a la forma de Estado como es la igualdad inter-territorial, o -en su versión socio-económica- la solidaridad. Se pueden hacer nuevas concesiones a los "diferenciales", pero siempre intentando una interpretación armónica y equilibrada de éstos para evitar la generación de nuevos privilegios ${ }^{33}$. Los anteriores "supra-principios" del sistema autonómico impiden en todo momento que la actualización de los derechos históricos de los territorios forales (Disposición Adicional Primera), o dicho de otro modo, la expansión al máximo de las singularidades territoriales, pueda hacer peligrar la unidad y solidaridad intercomunitaria ${ }^{34}$.

En este sentido, y como propuesta en perfecta sintonía con el principio algo más cercano a la "bundestrue» —o lealtad federal-, nos parece acertado el plan que ha presentado recientemente el Gobierno vasco al Ejecutivo central y las demás CC.AA., encaminado a articular un sistema de efectiva participación de éstas en el seno de los organismos comunitarios, donde tiene representación el Estado español; en concreto, mediante la presencia de representantes de las Comunidades en el pleno del Consejo de la Unión, la Comisión de Representantes

33 En este punto coincidimos nuevamente con la postura de Torres Vela, quien sostiene - ahora sí parece en calidad más de Presidente del Parlamento de una $\mathrm{CA}$ - que "Andalucía no tendría inconveniente en admitir situaciones específicas, siempre y cuando no supongan ni subordinación política de Andalucía, ni una situación de privilegio económico para otras Comunidades». Cit., págs. 20-21.

34 Vid. G. TruJlLLo, cit., pág. 20 , nota $n .{ }^{\circ} 6$. 
Permanentes (COREPER) y en los grupos de trabajo donde se sustancien asuntos relacionados con sus competencias normativas (legislativas y ejecutivas) $)^{35}$.

Ciertamente se trata de una iniciativa que encaja sin dificultad en el diseño de cualquier "federalismo cooperativo". Se acepta con ella por fin el principio de la participación multilateral de todas las Comunidades, en la medida en que ninguna recibe un tratamiento particularizado. La delegación autonómica - con independencia de la CA que en cada caso ostente la repesentación- actuaría en defensa de los intereses del conjunto.

El acierto de este tipo de planteamientos va más allá de la mera instrumentación de un procedimiento de colaboración de las CC.AA. en la política comunitaria del Estado. Podríamos considerarlo en cierto modo también como una respuesta posible, y constitucionalmente aceptable, a la reivindicación de una suerte de "co-soberanía" - nacional y territorial-, desde hace algún tiempo uno de los argumentos que centralizan el debate político sobre el Estado de las Autonomías.

Si se parte de la base de que la integración en una organización internacional como la UE supone la cesión de una buena dosis de aquella "soberanía nacional» ${ }^{36}$, es necesario admitir seguidamente que una buena parte de las políticas estatales se van a ver condicionadas inclusive más, subordinadas- por las decisiones que se adoptan en el seno de instituciones comunitarias. La integración europea repercute lógicamente sobre la autonomía real de las CC.AA., ya que restringe considerablemente, a su vez, la capacidad de autodeterminación decisión "política" de éstas. Por esta razón no debería existir demasiados inconvenientes para ampliar los mecanismos de colaboración paritaria de aquéllas en los procesos de toma de decisiones comunitarias del Estado. En estos canales se podrían admitir inclusive ciertas singularidades, en función tanto de las materias que inciden con mayor intensidad en los intereses específicos de las diferentes Comunidades, como dependiendo del mayor o menor nivel de voluntad institucional por participar en los mismos.

35 Vid. El País, miércoles 2 de junio de 1999, pág. 17.

36 Aunque matizada, eso sí, por la teoría de que en realidad lo cedido no es la titularidad, sino únicamente el "ejercicio" de la soberanía, de acuerdo con los términos literales del artículo 93 de la CE: "Mediante ley orgánica se podrá autorizar la celebración de tratados por los que se atribuya a una organización o institución internacional el ejercicio de competencias derivadas de la Constituciónn. 
En lo que respecta al problema de la autodeterminación, la enseñanza que se extrae de este fenómeno de globalización no es otra que la repercusión que ésta tiene sobre los principios jurídicos fundamentales del Estado-nación, condensados en la idea de supremacía e indivisibilidad del derecho y soberanía estatales. Por análogas razones, sería imprescindible proponer una nueva interpretación de aquella noción, tradicionalmente vinculada a una demanda que tiene como finalidad primigenia la secesión territorial. La mutación progresiva de estos conceptos requiere de un enfoque jurídico $y$ político contextualizado en una dimensión donde el poder y la soberanía están de hecho compartidos entre instancias y sujetos con ámbitos competenciales propios $^{37}$.

De todo lo afirmado hasta ahora habría que resaltar especialmente la idea de que en un Estado Constitucional es necesario resolver los problemas políticos con normas jurídicas. Sólo así la Constitución deja de ser un documento político para convertirse en derecho vinculante. Desde esta perspectiva hay que interpretar la teoría de la "mayoría suficiente" propugnada por el Tribunal Supremo de Canadá en la última Sentencia sobre la posible escisión de Quebec $^{38}$.

En nuestro ordenamiento constitucional no debería existir ninguna duda en principio sobre el alcance y cuantificación de esa «mayoría", pues ya se ha previsto en el Título X de la CE de 1978 tanto la proporción como el alcance territorial -el que debe tener: mayoría de dos tercios para la revisión completa y extraordinaria o completa (art. 168) y de tres quintos para la reforma ordinaria (art. 167), además de un referéndum nacional obligatorio $y$ potestativo en uno y otro caso.

Pero al formar parte del bloque de constitucionalidad, sería imprescindible a continuación proceder igualmente a la reforma de los

37 La conclusión a la que llegamos coincide con las ideas y planteamiento que ha hecho G. JÁUREGUI BERECIARTU, en "La autodeterminación en la perspectiva del Siglo XX|», Revista Vasca de Administración Pública, n. ${ }^{\circ} 41,1995$, pág. 819 y ss.

38 En todo caso, habria que hacer hincapié en la posición que defiende en la Sentencia de Agosto de 1998, rotundamente opuesta a permitir una posible conculcación del ordenamiento constitucional durante el eventual proceso de secesión de Quebec. Para el Tribunal Supremo canadiense, "cualquier intento de llevar a cabo la secesión de una provincia del resto de Canadá debe estar de acuerdo con lo establecido en la Constitución canadiense, ya que de lo contrario se violaría el orden legal vigente". 
EE.AA. afectados hipotéticamente por aquella modificación de la norma fundamental. La razón es bastante obvia: mientras no se cambie el sistema de fuentes de nuestro ordenamiento jurídico sólo pueden ser dentro de esta categoría de normas donde han de introducirse los posibles cambios que se aprueben en el seno de las instituciones políticas (Cortes Generales, Parlamento autonómico), bien de los "techos" de autogobierno territorial, bien de su estructura organizativa interna ${ }^{39}$.

Por consiguiente, y a menos que se quiera desvirtuar el carácter normativo de la Constitución - lo que implicaría automáticamente un regreso a las esencias decimonónicas del constitucionalismo liberal- la posibilidad de plantear un referéndum, o cualquier otra forma de decisión representativa y democrática, en lo que se ha denominado "ámbito de decisión" (vasco, especialmente) necesitaría una previa revisión constitucional. Sólo mediante esta especie de "reforma para/de la reforma" se podría legitimar el eventual ejercicio de un derecho a segregarse del Estado español, sin la participación de los ciudadanos que componen el resto de la comunidad nacional.

Estamos de acuerdo, pues, con los que piensan que hay que tomar la iniciativa ${ }^{40}$. El partido se ha jugado hasta hoy en campo contrario. A partir de ahora, los "otros" -que en el fondo son también parte de los nuestros- deben esperar, en nuestro terreno, una propuesta sólida en lo político y articulada jurídicamente, que integre sus aspiraciones particulares sin dejar de armonizarlas con los intereses del conjunto. Por esta razón, sigo pensando que la -llámese- reformulación o "relectura" del Estado autonómico en clave federal puede ser la solución a la voluntad, que ha de ser siempre democrática, de cada una de las partes.

39 Para López GUeRRA, pese a que la reforma de los EEAA cuenta en este sentido con claras ventajas de adaptación respecto de la rigidez de los procedimientos para la reforma constitucional, sin embargo, no sería improcedente plantearse la posibilidad de un desarrollo autonómico vía normativa legal, como mecanismo de ajuste a las necesidades de cada momento, al tiempo que se mejorarían los niveles de integración. Vid. "Modelo abierto y modelo cerrado del Estado de la Autonomías", cit., pág. 45-46.

40 Vid. Ramón Cotarelo, "Por qué lleva la iniciativa el nacionalismo", El País, viernes 22 de enero de 1999. 


\section{EL PROBLEMA VISTO DESDE LA COMUNIDAD AUTÓNOMA DE ANDALUCÍA}

Les propongo un ejercicio de imaginación: a través de un viaje en el tiempo supongamos una fecha determinada -28 de Febrero de 1980-.y un espacio concreto - Andalucía-, en el dilema de elegir ante una situación definida: el referéndum de iniciativa autonómica.

Ahora se trata tan sólo de imaginar que el resultado de aquella consulta popular hubiese sido uno muy distinto. Es decir, si en lugar de aquella mayoritaria expresión colectiva a favor de la construcción de una Comunidad Autónoma - como se sigue todavía denominando"del 151 ", se hubiese producido un tímido e insuficiente respaldo a ese mismo proyecto político al no superarse ese umbral que la CE de 1978 había impuesto a aquellas Regiones que intentaran -permítasenos el simil- entrar en la "primera división", esto es, dentro del grupo privilegiado donde ya tenían carta de naturaleza las llamadas «Nacionalidades Históricas".

Los mensajes que se proyectan y divulgan desde la experiencia autonómica andaluza son bastante explícitos, a nuestro modo ver: Andalucía representa en primer lugar la superación del trato privilegiado que la Constitución otorga aparentemente a unas Comunidades dotadas de algún signo de distinción foral o histórica.

Efectivamente, en retrospectiva, y frente una lectura de la asimetría explícita de los mecanismos procesales para acceder al autogobierno regional, simbolizó la posibilidad de eliminar no sólo la ralentización del Estado autonómico, sino también el riesgo de una "administrativización» del Estado autonómico.

Pero en una dimensión prospectiva, Andalucía seguirá teniendo también un "valor emulativo" respecto de las demás CC.AA. Como instancia anti-simetría, proyectará sobre el conjunto del sistema la idea de que la originaria discriminación en los procesos fundacionales no tiene por qué traducirse en todo caso en una permanente diferenciación cualitativa de techos competenciales. Creemos no equivocarnos al afirmar que la apuesta esencial de la CA de Andalucía se concreta en la asunción real de los principios de igualdad y solidaridad, junto a la articulación institucional de un diseño del modelo de Estado en clave federal. Sin olvidar que este proyecto se incardina en un escenario real, donde la soberanía nacional se encuentra efectivamente compartida con la UE, lo que exige plantear instrumentos que permitan a todas las CC.AA., en términos igualita- 
rios, participar de su ejercicio junto a las instituciones centrales del Estado 41.

Por otro lado, Andalucía proyecta la imagen real -que no realidad imaginaria- de un nuevo tipo "hecho diferencial" basado, bien en una voluntad de verdadera autodeterminación política en el marco constitucional, bien en una realidad socioeconómica de donde emana sus señas de identidad territorial.

Aunque somos conscientes de que el perfil y la base constitucional de los "hechos diferenciales" sigue siendo una tarea pendiente o cuanto menos inconclusa ${ }^{42}$, no nos cabe duda de que no ha habido en ningún otro territorio español una expresión tan intensa de una mayoría social en favor de un proyecto político propio. De este modo, y si se traduce hecho diferencial por «voluntad política diferencial» (López Aguilar), lo cierto es que Andalucía ha puesto de manifiesto de manera más explícita que ninguna otra la voluntad de ser diferentes.

Porque no creemos que esta singularidad pueda medirse en términos de estabilidad de una fuerza política nacionalista que defiende, con métodos o ideología más o menos radicalizada, un supuesto sentimiento de la nación-pueblo del territorio de la Comunidad.

El escaso eco en Andalucía de los proyectos en favor de una remodelación de la forma de Estado tiene que ver bastante con el fracaso de un partido nacionalista-regionalista andaluz.

Al analizar las causas de la frustrada tentativa por consolidar en nuestra CA una fuerte opción política de esta naturaleza, representada fundamentalmente por el Partido Andalucista (PA), hay que retomar el hilo de los acontecimientos a partir de 1977. En efecto, durante un período comprendido entre este año y 1981, la situación política en Andalucía parecía abonada para el desarrollo de un partido que intentara

41 En el momento en que se redacta este trabajo acaba de anunciarse ante los medios de comunicación una propuesta de la Junta de Andalucía (14 de Julio de 1999) para establecer los mecanismos de participación de los representantes autonómicos en el Consejo de Ministros de la UE, junto a los miembros delegados del Ejecutivo estatal. La aprobación definitiva de esta iniciativa depende de la Conferencia Para Asuntos Relacionados con las Comunidades Europeas.

42 Vid. J. F. López Aguilar, "Constitución autonomía y hecho diferencial. El Estado Autonómico y el "hecho diferencial constitucionalmente relevante", en Cuadernos de Derecho Público, n. 2, 1997, INAP, pág. 25 y ss. 
articular electoralmente los intereses inmanentes a una singularidad socio-económica incuestionable de la Región 43 .

Hasta entonces, el PSA, junto a Convergencia i Unió (CiU), habían logrado la mayor representación de un partido de ámbito no estatal en el Congreso de los Diputados. $Y$ sin embargo, actualmente, no puede considerarse a este partido más que como una "típica" formación bisagra que, no obstante, resulta imprescindible para la estabilidad gubernamental - y en general política- de la CA de Andalucía ${ }^{44}$.

En la actualidad, y pese al relativo incremento en número de votos -o quizás sería mejor hablar de conservación del voto "recuperado" en las anteriores elecciones autonómicas- en los últimos comicios municipales (1999), el nacionalismo andaluz, representado por este PA, sigue teniendo un escaso protagonismo en la vida política de la - pese a todo, más votada- opción nacionalista, un factor que condiciona como es lógico el debate sobre la posición de nuestra Comunidad en torno al futuro del Estado autonómico.

Sin embargo, la realidad en el presente pudiera haber sido otra bien diferente si no se hubieran cometido errores de bulto en la estrategia seguida por este andalucismo político contemporáneo45. A nuestro entender, la marginalidad del PSA-PA es la herencia todavía de aquella indefendible $-y$ contradictoria para un partido de estas características ideológicas- posición mantenida en relación con el proceso

43 Vid. Inmaculada Barroso Benitez y María Teresa Salvador Crespo, "Regionalismo andaluz. Posibles causas del fracaso de un partido regionalista en Andalucía", Revista Mágina, UNED, Jaén, n. ${ }^{\circ}$, pág. 123.

44 Me remito al estudio que hago sobre la "esperpéntica" - por calificarlo de algún modo- IV legislatura del Parlamento de Andalucía, en La forma de gobierno en Andalucia, Valencia, 1999.

45 Aunque se trata de una opinión personal, fruto más que de la impresión reflexiva que del examen estrictamente científico - lo que no estoy seguro tampoco de que pudiera llevarse a cabo--, tengo la sospecha de que la mayoria de los grupos políticos intentan extraer de la iniciativa que promueve Blas Infante antes y durante la segunda República, bastante minoritaria y por supuesto puramente germinal, una verdadera seña de identidad nacional, desde la que construir la idea histórica de un hecho diferencial andaluz. Entre los hechos más destacados durante este período merecen consignarse la fundación de un Centro Andaluz" en Sevilla (1916), la celebración de la primera "Asamblea Regionalista» en Ronda (1918), la elaboración en 1932 de unas "Bases para el Estatuto Andaluz" y la elección del propio Blas Infante como Presidente honorífico de la "Junta Regional" (1936).

Normalmente, sin embargo, la apelación al movimiento andalucista de Infante, más allá de sus múltiples conmemoraciones y celebraciones con rango oficial no pasa de ser un gesto testimonial, con muy poca repercusión efectiva en las propuestas políticas que se hacen al electorado andaluz. 
de iniciativa autonómica, a través del canal constitucionalizado en el artículo 151, al apoyar en ese momento al entonces partido en el Gobierno nacional (UCD), partidario de utilizar la vía ralentizada e inferior en cuanto a techo competencial del artículo 143 . Ha sido casi con toda probabilidad el precio de esta alianza el factor que ha arrastrado al nacionalismo andaluz a una "travesía del desierto" cuyo final no acaba de atisbarse ${ }^{46}$.

En buena medida el nacimiento y desarrollo de este andalucismo político tiene como punto de partida, así como su referente esencial, en una singularidad estructural y económica, marcada por el inferior nivel de desarrollo económico de la Comunidad respecto a la mayor parte del resto del Estado. De esta diferencia, o - por qué no decirlo- discriminación territorial, va a emanar una conciencia regional que encontrará en el referéndum sobre el proceso autonómico su mejor expresión política.

Ahora bien, si la supuesta identidad andaluza se configura como una determinada conciencia social sobre el inferior nivel de progreso socio-económico, más que de particularidades de carácter cultural, histórico o lingüístico, cabría plantearse si, una vez superado ese factor objetivo de la realidad andaluza, dejará de tener sentido reivindicar un tratamiento particular -la proclamada «deuda histórica»— sobre la base de un agravio comparativo histórico ya superado. Pero además, si la

46 Se han señalado otras causas adicionales para explicar la escasa implantación electoral del Partido Andalucista. Aunque algunas de ellas serían «exógenas" a la realidad política de la Comunidad (la limitada proporcionalidad del sistema electoral, que beneficia preferentemente a los partidos de ámbito estatal), la mayoría encuentran explicación en factores internos, bien del sistema de partidos autonómico, bien del propio PA. Apuntaremos en este doble sentido los factores que nos parecen más relevantes: la dispersión territorial del voto andalucista, la indefinición fluctuante de su ideología (de ser un partido de izquierdas a configurarse como opción de centro-derecha) en función de la coyuntura política y de pactos, lo que se ha denominado "vampirismo" del discurso andalucista por los partidos estatales, o la frecuente celebración conjunta de los comicios regionales y generales (1986, 1994, 1996). Vid. I. Barroso y M.a Teresa Salvador, cit., pág. 130 y ss. Para un análisis minucioso y exhaustivo sobre la evolución electoral en Andalucía resultan imprescindibles, J. Montabes Pereira, "El proceso político andaluz", en J. LACOMBA, Andalucia y los andaluces. Propuestas para un debate, Málaga, 1992; J. CazorLA, "Estructura social y comportamiento político en Andalucía», Cuenta y Razón, n. ${ }^{\circ} 40$, 1988; J. R. Montero Gibert y M. Torcal, "Autonomías y Comunidades Autónomas en España: preferencias, dimensiones y orientaciones políticas", Revista de Estudios Políticos, n. ${ }^{\circ}$ 70, 1990; J. R. Montero y A. Porras, "Las elecciones de 23 de mayo de 1982 en Andalucían, en J. Pérez Royo y A. Porras (eds.), El Parlamento de Andalucia. Análisis de la Primera Legislatura (1982-1986), Madrid, 1987. 
señas de identidad diferenciales de Andalucía se forman esencialmente a partir de una demanda social para hacer frente a esta realidad, cuando ésta ya no exista -o sea otra muy distinta- habrá que buscar otros elementos distintivos con los que seguir manteniendo una conciencia como comunidad diferenciada.

En cualquier caso, que esta identidad colectiva sea patrimonio de un partido, concretamente de aquél que en teoría se presenta como exponente único del andalucismo político resulta más que discutible. Nuevamente los elementos fácticos del contexto andaluz ponen de manifiesto algunos inconvenientes en este sentido. Porque ni en el tejido social, en forma de instituciones o corporaciones que canalicen ese sentimiento nacional, ni electoralmente, a través de opciones políticas que hayan capitalizado las preferencias autonomistas, ha llegado a consolidarse como alternativa de gobierno un grupo nacional-andalucista. La razón reside probablemente en la dialéctica que incide con mayor intensidad en la competición electoral en Andalucía, marcada siempre, $y$ todavía, por los clásicos extremos ideológicos "derecha»"izquierda", antes que por el denominado "cleavage" territorial centroperiferia.

Por nuestra parte, nos inclinamos a pensar que la combinación que tendría lugar entre aquella concepción de la identidad regional basada en factores diferenciales de naturaleza socio-económica con la percepción hegemónica aún en Andalucía de la dialéctica ideológica (derecha - izquierda), van a obstaculizar en todo momento el desarrollo de un proyecto político que, al estilo de otros nacionalismos periféricos, pretenda asentarse como fuerza política mayoritaria -o alternativa de gobierno- en la Comunidad. La lógica de la experiencia así lo ha demostrado hasta hoy: mientras que la singularidad territorial reivindicada frente al centro político e institucional no se mida en términos de particularismos culturales acentuados o exponentes lingüísticos o forales propios, sino en niveles inferiores de progreso económico y estructural, siempre estará en mejores condiciones de monopolizar ese «andalucismo políticon el partido que ofrezca una alternativa de progreso, lo que normalmente ocurre con las formaciones encuadrables a la izquierda del espectro ideológico. Esto explicaría por qué en otras Comunidades los partidos nacionalistas obtienen un rendimiento electoral mucho mayor de la defensa de la identidad nacional, al no tener necesidad de competir por señas de identidad socioeconómicas con los partidos que tradicionalmente han representado los intereses de esta naturaleza.

Es posible, por último, que cualquier opción fundamental o preferentemente regionalista tenga poco éxito entre un electorado que 
manifiesta en su mayoría una identidad "dual" (español y andaluz simultáneamente), siendo minoría aquellos que declaran poseer una suerte de "mono-identidad" (andalucista o españolista).

En cualquier caso, no hemos podido constatar - quizás se trate de una apreciación equivocada - un verdadero discurso institucional dentro de la CAA en relación con el futuro del Estado Autonómico. En lo que respecta a este tema, no se ha aprobado en el órgano por excelencia de representación política ninguna resolución o proposición no de ley de la que se desprenda un proyecto alternativo a los que se han reivindicado desde otros Parlamentos territoriales.

Falta en el discurso de la clase política andaluza una toma de posición "positiva" a propósito de una futurible remodelación de la Constitución territorial ${ }^{47}$. Queremos decir que todavía no se ha llegado a proponer desde Andalucía un diseño alternativo al que se encuentra en vigor actualmente. La inercia se traduce muchas veces en la actitud defensiva - traducido como el rechazo a un presunto «agravio comparativo"- que se pone de manifiesto contra aquellos proyectos normativos que desde el Estado "estiran al máximo las posibilidades que ofrece el modelo constitucionalizado 48 . Nos estamos refiriendo a las impugnaciones presentadas contra el sistema de financiación implantado a partir de la reforma de 1996 de la LOFCA. La argumentación de estos recursos se apoya fundamentalmente sobre la potencial lesión que sobre los elementos estructurales que caracterizan al Estado Autonómico produce la territorialización del impuesto sobre la renta de las personas físicas. En efecto, la CAA asume aquí voluntariamente el protagonismo en una defensa - casi numantina, diríamos- de los dos principios más emblemáticos de la forma de Estado constitucionalizada: igualdad y solidaridad. El objetivo fundamental a perseguir será

47 Hemos citado ya, y ahora lo subrayamos como planteamiento "oficioso" que puede considerarse representativo no obstante de la posición de la CA de Andalucía, la conferencia de ToRres VELA, "Andalucia en el Estado Autonómico". Conferencia pronunciada en la Fundación Campalans, Barcelona, 1997. Asimismo, y falta de otros elementos de referencia, creemos necesario consultar los argumentos del Recurso presentado ante el TC contra la Ley de Presupuestos Generales del Estado de 1998 (Ley 65/1997), así como los recursos contra el nuevo sistema de financiación autonomica (Recursos 1105/97 y 1107/97).

48 Un caso paradigmático de esta actitud se observa en el Recurso planteado por la Junta de Andalucía contra la Ley estatal que crea el Parque Nacional de Sierra Nevada. El motivo central del mismo se centra en que, mientras que se ha otorgado a la Generalidad de Cataluña la gestión en exclusiva de los Parques nacionales situados en territorio de esa Comunidad Autónoma, esa misma gestión debe ser compartida con el Estado en el caso de los Parques Nacionales andaluces. 
simplemente el rechazo a toda suerte de privilegio o status particular con el que el Estado intente compensar indirectamente a alguna Comunidad por su contribución a la estabilidad política del gobierno central.

La conclusión podría resumirse, por tanto, en un notable inmovilismo conservador. Se prefiere la solvencia del presente sistema constitucional que el riesgo de una aventura hacia fórmulas federales donde, probablemente, residiría la mejor solución para evitar la discriminación implícita en los actuales planteamientos asimétricos.

Para concluir, un recordatorio prácticamente olvidado. Apenas se hace referencia doctrinalmente, como tampoco se insiste tampoco desde la esfera política, pero convendría recordar que Andalucía tiene un indiscutible rango de "Nacionalidad". Al menos no se puede deducir otra cosa de su Estatuto, norma fundacional de las instituciones territoriales donde reza textualmente lo siguiente:

«1. Andalucía, como expresión de su realidad histórica y en ejercicio del derecho al autogobierno que la Constitución reconoce a toda nacionalidad, se constituye en Comunidad Autónoma, en el marco de la unidad indisoluble de la nación española, patria común indivisible de todos los españoles.

2. El Estatuto de Autonomía aspira a hacer realidad los principios de libertad, igualdad y justicia para todos los andaluces, en el marco de igualdad y solidaridad con las demás nacionalidades y regiones de España.

3. Los poderes de la Comunidad Autónoma emanan de la Constitución y del pueblo andaluz en los términos del presente Estatuto".

De un precepto como el anterior siempre cabe matizar el sentido simbólico de una buena parte de lo que allí se declara. Pero sin dejar de ser conscientes de lo que aquí se contiene como "concesiones a la galería", no obstante todavía existen razones para reconocer algunas de sus potencialidades, cuando no de ciertas contradicciones en que se incurre precisamente por exagerar esa nota de solemnidad institucional.

Lo que parece destacar de esta presentación inicial no es otra cosa que la auto-afirmación de Andalucía en cuanto "Nacionalidad" con su propia «identidad histórica». Ambas notas la sitúan al mismo nivel que las demás Nacionalidades históricas que han tenido un implícito, pero a la vez evidente, reconocimiento constitucional (Disposición Transitoria Segunda). 
En segundo lugar, se estaría proponiendo la plena asunción de los principios constitucionales que configuran el modelo territorial de Estado. La referencia a la "indisoluble unidad" va acompañada, de este modo, por los compromisos que adquiere la Comunidad con respecto a los valores de igualdad, justicia y libertad; a los que habría que añadir una especial insistencia en los principios que sintetizan el rechazo a cualquier expresión de privilegio inter-territorial (solidaridad e igualdad con las otras CC.AA.).

Finalmente nos llama poderosamente la atención lo que -a nuestro juicio- no puede ser otra cosa que un exceso verbal del poder estatuyente. Se trata de la referencia que se hace en el apartado tercero al "pueblo andaluz" como una especie de sujeto dotado de soberanía de donde emanarian los poderes e instituciones previstas en el Estatuto de Autonomía. Nos sorprende realmente cómo en esta declaración de principios se ha intentado reforzar la esencia nacionalista, hasta el punto de diseñar una fórmula a todas luces incompatible, desde una óptica constitucional, con el concepto de soberanía popular (art. 1-2. $\left.{ }^{\circ}, \mathrm{CE}\right)^{49}$.

La explicación hay que buscarla —como era de esperar- en la tendencia homogeneizadora que caracteriza el Estado Autonómico españo|50. De ahí que esa mención al "pueblo co-soberano" de la disposición que encabeza el EAA no venga sino a importar una fórmula análoga utilizada anteriormente por el EA del País Vasco («pueblo vasco o Euskal-Herria", art. 1); en este sentido se destacaría incluso con respecto a otras Nacionalidades con una conciencia nacional teóricamente más desarrollada, en cuyos Estatutos, aunque con un sentido análogo, no se hace referencia expresa al pueblo de la Comunidad: Cataluña ("pueblo», art. 1-3. ${ }^{\circ}$ ) o Galicia («pueblo», art. 1-3. ${ }^{\circ}$.

Si estuviésemos de acuerdo con una interpretación literal de los términos de la norma estatutaria diríamos que se ha querido apoyar la idea de una "territorialización» de la soberanía. Es más, si hubiese que

49 La fórınula constitucional tiene un significado teóricamente análogo al del EA de Andalucía; únicamente cambia la expresión, "pasiva" en el primer caso, de la legitimación del poder político estatal («soberanía nacional reside en el pueblo español, del que emanan los poderes del Estadol, frente a un enunciado positivo del Estatuto andaluz (los poderes de la Comunidad Autónoma emanan de la Constitución y del pueblo andaluz...").

50 Vid. G. Ruız-Rıco Ruız, "La forma de gobierno autonómica en España», en Formas de gobierno y sistemas electorales (G. RuIz-Rıco y Silvio GamBINo, coords.), Valencia, 1997, pág. 525 y ss. 
replantearse en el futuro la hipótesis de una reforma constitucional orientada en esa dirección - véase la propuesta del nacionalismos catalán- no sería posiblemente imprescindible reformar el EA ya que, al menos para Andalucía,y en contra de lo que pudiese pensarse, se cuenta ya con una fórmula estatutaria apropiada, cercana incluso a la configuración federal de una soberanía originaria que se limita constitucionalmente por decisión propia.

Pero hay una nota distintiva más que marca diferencias cualitativas con respecto a las normas fundacionales de las llamadas Nacionalidades Históricas. Éstas no contribuyen en nada - por lo menos no lo hacen desde el punto de vista estatutario- a la realización de los principios fundamentales del Estado Autonómico. Sin embargo, el Estatuto andaluz va a enfatizar una especial aportación de la Comunidad a la integración política, social y económica del conjunto del Estado. Lo que se contiene en el artículo representa - creemos- no sólo una mera declaración de buenas intenciones sino, por el contrario, un compromiso, auténticamente diferencial, que deberá inspirar en todo momento una actuación con unos fines predeterminados: desde la conservación de la unidad territorial del Estado a la progresiva igualación socio-económica a través de un ejercicio solidario del derecho a la autonomía.

Precisamente esta falta de neutralidad ideológica, al igual que esa expresión fehaciente del principio de "lealtad federal», configuran una especie de deber institucional contra cualquier pretensión de orientar el modelo de Estado hacia otros fines y principios. Por qué no decirlo también: en cierto modo este compromiso constituye un hecho diferencial "institucional» 51 de naturaleza jurídico-estatutaria que singulariza la posición de la CA de Andalucía en el conjunto del Estado52.

51 Utilizamos la expresión "hecho diferencial institucional» en un sentido distinto al que emplea Rubio Llorente, como sinónimo de existencia de un partido nacionalista fuerte y con presencia en el Parlamento central. Vid. F. RUBIo LLORENTE, intervención dentro de la monografía "Ante el futuro del Senado" (E. Albertí, coord.), Barcelona, 1996. Por nuestra parte, la versión "institucional" del hecho diferencial andaluz es aquella que expresa en términos jurídico-estatutarios no sólo una voluntad política colectiva de acceder al máximo nivel de autogobierno regional, sino también el propósito de contribuir como Comunidad Autónoma a la realización de los principios fundamentales del modelo de Estado (igualdad y solidaridad).

52 La proyección "exterior" de ese compromiso contrasta con la mención que aparece en el Estatuto de una Nacionalidad Histórica como Galicia, en cuyo Estatuto (art. $1-2 .^{\circ}$ ) se indica la obligación de los poderes de esa Comunidad de promover la solidaridad "entre todos cuantos integran el pueblo gallego" ("solidaridad internan). De otro lado, la preocupación institucional de la Comunidad Autónoma 
Todavía en el marco estatutario encontramos los elementos que confirman la concepción "instrumental» de la autonomía andaluza53. En efecto, la concesión del autogobierno regional representaba $-y$ así además se percibía socialmente-un método para superar la desigualdad histórica de la Región. Sobre la base de este "leif motive" se entiende mejor que el EA enfatizara los objetivos progresistas que permitían la superación de un situación claramente discriminatoria que se ha padecido durante mucho tiempo desde el punto de vista del desarrollo económico. Por este motivo también, la norma fundacional andaluza se ha preocupado, más que ningún otro Estatuto, de marcar los compromisos institucionales básicos de la Comunidad en su artículo 12.

Como si tratase de una "Constitución paralela», se asumen como propios los principios que estaban ya consagrados en la estatal: igualdad y libertad reales y efectivas, igualdad entre sexos, la superación de cualquier expresión de discriminación laboral, cultural, económica y política. Pero junto a los anteriores elementos, en plena sintonía con valores constitucionales de alcance general, el EA de Andalucía va hacer hincapié en una dogmática propia, al orientar el ejercicio de sus poderes de autogobierno hacia la consecución de unos objetivos sociales, que implícitamente estarían dibujando los rasgos esenciales de la singularidad socio-económica de Andalucía: pleno empleo, acceso a la educación, justa distribución de la renta y la riqueza, retorno de los emigrantes, calidad de vida y medio ambiente, protección del patrimonio histórico, sistema de comunicaciones eficaz, desarrollo industrial, reforma agraria (art. 12).

A sensu contrario, o mediante una lectura inversa de lo que allí se ha marcado en forma de objetivos sociales, podríamos afirmar que el EA está de esta manera proporcionando la imagen exacta del "hecho diferencial» andaluz. Solamente habría que añadir al anterior, la Disposición Adicional Segunda del mismo Estatuto ${ }^{54}$, para reconocer en

andaluza va a ser emulada por algunos Estatutos aprobados más tarde por otras CCAA mediante enunciados muy similares a aquél que han tomado como punto de referencia: art. 1-2. ${ }^{\circ}$ del Estatuto de Castilla-León y art. 1-2. ${ }^{\circ}$ del Estatuto de Madrid.

53 Así se titula exactamente- "Andalucía en el Estado Autonómico"- la conferencia dictada por J. ToRREs VelA en la Fundación Campalans, Barcelona, 1997.

54 El contenido de esta Disposición Adicional, aunque manipulado por intereses partidistas a veces, representaría la reivindicación "nacional" más significativa de la CA en sus relaciones con el Estado:

"Dadas las circunstancias socioeconómicas de Andalucia, que impiden la prestación de un nivel mínimo en alguno o algunos de los servicios efectivamente transferidos, los Presupuestos generales del Estado consignarán, con especifica- 
ambos preceptos el punto de partida y la explicación de aquella voluntad política, en favor de un autogobierno de primer orden, manifestada en el referéndum sobre iniciativa autonómica. Solamente desde estas premisas cabe esperar que Andalucía pueda contribuir a la remodelación de la Constitución territorial. Por ello, la actitud de esta CA será siempre contraria al eventual reconocimiento de estatutos especiales donde se contiene sin duda el fundamento de un tratamiento privilegiado.

ción de su destino y como fuentes excepcionales complementarias una asignaciones complementarias para garantizar la consecución de dicho nivel mínimo".

Como puede observarse, desde una perspectiva jurídica strictu sensu no nos parece demasiado correcto imponer al Estado desde una norma estatutaria una obligación -asi se desprende de la utilización del verbo en futuro imperativo, "consignarán"- que además depende en gran medida de las disponibilidades presupuestarias de aquél. Obviamente la interpretación que ha de hacerse de esta Disposición Adicional del Estatuto ha de hacerse más en clave "política" que juridico-normativa, reorientándola más - como ha sucedido en la práctica- hacia su instrumentación "interna", es decir, como una demanda institucional que se dirige desde la Comunidad al poder político estatal. 